\title{
A (DE)FORMAÇÃO PELA ESCOLA: REPRESENTAÇÕES DE PROCESSOS FORMATIVOS NA TRILOGIA AUTOBIOGRÁFICA DE ELIAS CANETTI ${ }^{1}$
}

\section{RODRIGO MATOS DE SOUZA}

Centro Universitário Jorge Amado

Faculdade São Salvador

\section{ELIZEU CLEMENTINO DE SOUZA}

Universidade do Estado da Bahia

RESUMO O artigo analisa questões relacionadas às escritas autobiográficas das obras A língua absolvida (2010a), Uma luz em meu ouvido (2010b) e $O$ jogo dos olhos (2010c), de Elias Canetti, escritor judeu sefardita, de origem búlgara, nacionalidade inglesa e residência suíça, enfocando os processos formativos que permeiam a Trilogia $\mathrm{Au}-$ tobiográfica que compôs o corpus de análise literária da pesquisa. Entende-se que o escritor compôs, com sua escrita autobiográfica, uma tentativa, no âmbito da ficção, de tratar de temas formativos, para além da escolarização e de seus paradigmas mais frequentes. Do ponto de vista metodológico, este estudo se desenvolve como uma bricolagem hermenêutica pela qual a produção literária do autor é revisada, no contexto cultural em que se produziu o sujeito narrador-personagem-autor da autobiografia, deixando que os conceitos e as discussões aflorem, ao longo do texto, à medida que necessários a determinados aprofundamentos. 0 trabalho discute as representações da relação professor-aluno, à luz da teoria melichiana, localizadas em duas imagens, a do mestre e a do professor, que, para além de qualquer dicotomia, evidencia a dimensão ética dessas inscrições, o dizer (do professor) e o mostrar (do mestre), como duas formas expressivas. 0 que se pode deduzir dessa diferenciação é que o mostrar, e o que ele acarreta - a ética, a estética e a religião - não pode se fundamentar no dizer, em uma teoria científica ou em uma demonstração, porque o que se pode mostrar não se pode demonstrar.

Palavras-chave: Formação. Autobiografia. Educação.

1 Pesquisa desenvolvida no Grupo de Pesquisa (Auto)biografia, Formação e História Orla com Financiamento da CAPES. 
ABSTRACT THE (MISS) FORMATION IN SCHOOLING:

REPRESENTATIONS OF FORMATIVE PROCESSES IN

\section{ELIAS CANETTI'S AUTOBIOGRAPHICAL TRILOGY}

This article presents an analysis on issues pertaining to the autobiographical writings in works like The Tongue Set Free, The Torch in My Ear and The Play of the Eyes, all by Elias Canetti - the Sephardi Jew, Bulgarian-born, British writer who resided mostly in Switzerland focusing on the formative processes pervading the Autobiographical Trilogy which is comprised in the corpus of the literary analysis in this study. The author produced with his autobiographical writing an attempt, in fiction, on addressing formational topics beyond schooling and its more ordinary paradigms. From a methodological point of view, this study was developed with the use of a hermeneutical bricolage, which made it possible to review the author's literary work and his cultural background, from which emerges the narrator-character-author individual in the autobiography, allowing key concepts and discussions deriving thereof to flourish, throughout the study, insofar as certain in-depth considerations were needed. This article examines representations of the teacher-student relationship, in light of Melich's theory, which are centered on two images: that of the professor and that of the master. Beyond any dichotomy, these images reveal the ethical dimension of two distinct ways of imprinting lecturing (professor) and showing (master) - as two expressive forms. What one can derive from this distinction is that the act of showing, and what it conveys - ethics, aesthetics and religion - cannot be substantiated in the act of lecturing, in a scientific theory or in a demonstration, because what can be shown cannot be demonstrated.

Keywords: Formation. Autobiography. Education.

\section{LA (DE)FORMACIÓN POR LA ESCUELA:}

\section{REPRESENTACIONES DE PROCESOS FORMATIVOS EN LA TRILOGÍA AUTOBIOGRÁFICA DE ELIAS CANETTI}

Este artículo analiza cuestiones relacionadas a las escrituras autobiográficas de las obras La Lengua Absuelta (2010a), Una luz en mi oído (2010b) y El Juego de los Ojos (2010c) de Elias Canetti, escritor judío sefardí de origen búlgara, nacionalidad inglesa y residencia suiza, concentrándose en los procesos formativos que impregnan la Trilogía Autobiográfica que compone el corpus de análisis literaria de la investigación. Se entiende que el autor ha compuesto con su escrita autobiográfica una tentativa, en el ámbito de la ficción, de tratar de 
temas formativos más allá de la escolarización y de sus paradigmas mas frecuentes. Del punto de vista metodológico, esta investigación, fue desarrollada como una bricolage hermenéutica, en la cuál se revisó la producción literaria del autor y su contexto cultural, en el que fue producido el sujeto narrador-personaje-autor de la autobiografia, dejando que los conceptos y los debates derivados emerjan a lo largo del texto, en la medida en que fuesen necesarias y determinadas profundizaciones. Este trabajo discute las representaciones de la relación profesor-alumno, a la luz de la teoría melichiana, localizada en dos imágenes, la del maestro y la del profesor, que, más allá de cualquiera dicotomía, evidencia la dimensión ética de estas inscripciones, el decir (del profesor) y el enseñar (del maestro) como dos formas expresivas. Lo que puede deducirse de esta diferenciación es que el enseñar, y lo que deviene de el - la ética, la estética y la religión - no puede se fundamentar en el decir, en una teoría científica o en una demostración, pues lo que se puede enseñar no se puede demostrar.

Palabras clave: Formación. Autobiografía. Educación.

Sobre a relação de Elias Canetti com a escola algo já foi dito (CATANI, 1990-1991; SILVA, 1998; ARAÚJO, 2004; OSINSKI, 2009), especialmente no Brasil,2 onde os estudos de sua Trilogia Autobiográfica, centrados no primeiro volume, $A$ lingua absolvida, revelam certo interesse sobre as representações de alternativas formativas ao ensino formal, como provocação à história da educação, ou no sentido de procurar outras abordagens impressas da relação entre professores e alunos. Esses escritos nos falam de um Canetti que inicia sua relação com a escola, com os professores e com a pedagogia, que não é necessariamente a de seu tempo, mas a de cada um dos sujeitos que se apresentou como docente, em suas diversas classes,

2 Este uso da Trilogia Autobiográfica canettiana como mote para uma discussão educacional, no âmbito acadêmico, é uma ocupação brasileira, marcada pela primeira abordagem feita por Denice Catani (19901991), e o que foi escrito posteriormente guarda certa relação direta ou tributária com este estudo inicial. Não encontramos nenhum registro desse interesse fora de nossas fronteiras, e são muitos os usos de Canetti, mas, ao que tudo indica, o interesse educacional por sua obra é um fenômeno acadêmico brasileiro (SOUZA, 2014). nos diferentes países por que passou, deixando entrever a difícil relação que sujeitos como ele mantêm com a escola.

É preciso reafirmar que Canetti foi um sujeito imerso na cultura letrada, oriundo de um horizonte cultural, o judaísmo, que historicamente valoriza o escrito, a leitura e as profissões intelectuais (justamente aquelas que se pode carregar consigo numa diáspora) e pertencia a um núcleo familiar que exigia do sujeito dedicação ao conhecimento e às artes, especialmente a literária (SOUZA, 2015). A escola, em seu aspecto coletivo, reprodutivista e de controle das massas, tem muita dificuldade em lidar com os diferentes, aqueles que não se adaptam aos procedimentos standards, que pressupõem um sujeito estável e único. Esse lugar, a escola, tem dificuldade em aceitar quem não depende dela, exclusivamente, em trabalhar com os sujeitos que não conseguem/ querem se inscrever-em seu discurso.

A constante reinscrição do discurso pedagógico num exercício já bem conhecido de adesão a uma verdade tão intransponível 
quanto incerta, mas que em nosso tempo se cristaliza na produção de um discurso a ser venerado, museificado, parece ser uma realidade tão humana quanto pedagógica. Precisamos da verdade e, como desconfiamos da própria verdade em que nos inscrevemos, estamos sempre em busca de sua atualização, de uma nova interpretação única que nos satisfaça temporariamente (o que implica uma concepção - também provisória, mas aceita como única - de professor e aluno).

A pedagogia como disciplina e ordenação das regras, ao impor o afastamento da dispersão e pôr-se a serviço da interpretação única, abstrai a história, exclui o que desconcerta e é inesperado. Garantia de tranquilidade, porque providência para a exclusão do erro, a pedagogia agarrada à ilusão dos controles justifica-se elaborando o discurso do 'museu': classifica e organiza, isola e dirige o olhar, além de imprimir os folhetos que ensinam a percorrer os conhecimentos selecionados como dignos, destituídos do seu poder de sedução e inquietação. (CATANI, 1990-1991, p. 26)

A resistência de Canetti em se submeter aos processos educativos formais (SOUZA, 2015), ao mesmo tempo em que se encanta com a própria ideia de escola, antes de conhecê-la, e com os jovens professores progressistas de Zurique são um bom exemplo de como a escola pode ser percebida de forma muito diversa por um mesmo sujeito. Encontrar a escola como lugar de aprendizagem, ao mesmo tempo em que nela se experimenta o horror da perseguição antissemita, junto a uma pedagogia prescritiva e enraizada em métodos pedagógicos arbitrários e personalistas, é uma generosidade do autobiógrafo, talvez mais por redimir ou distinguir alguns poucos professores que the proporcionaram algum desafio no ambiente duro das salas de aula por onde passou.

Sua relação com a escola não começa com o primeiro dia de aula, mas se inscreve numa dimensão representacional, quando se vê querendo compartilhar de um ambiente do qual não faz parte, mas deseja ardentemente, pois sabe que lá se ensinam os códigos com os quais os adultos, seus pais em especial, se comunicam. Sua prima, Laurica, ao retornar da escola, desenvolve um jogo com ele, que consistia na oferta seguida da recusa de lhe mostrar o caderno com as letras azuis, que, desde o primeiro momento em que o viu, provocou nele certa fascinação (CANETTI, 2010a). A experiência de perder por algumas horas a companheira de brincadeiras, ao mesmo tempo em que esta avançava, aos olhos do garoto, num terreno que era seu, pelo menos seu desejo mais ardente, provocou-lhe inveja. Catani, Bueno e Sousa (2000) nos falam de como se pode despertar este amor incerto pelo que não se conhece.

A existência de irmãos, irmãs, primos e primas mais velhos experimentando a vida na escola é [...] algo que aguçou a curiosidade, ou que começou a fazer parte do universo infantil por conta da perda temporária do parceiro de brincadeiras e o consequente sentimento de solidão. [...] A inveja [...] da situação vivida pelo outro, a visão de crianças uniformizadas passando pela rua, o convívio com irmãos e outros parentes na hora das lições de casa são alguns dos motivos que aparecem simultaneamente à menção do desejo de também partilhar a experiência de frequentar a escola. (2000, p. 155-156)

Sua experiência diária de esperar a prima transformou-se em sofrimento, para o qual a cura ainda estava distante, em tempo e espaço (ele só entraria para a escola, na Inglaterra, aos sete anos, e na ocasião do evento contava apenas cinco). Assim, ante a provocação da prima, resolve cometer um ato extremo:

Assim teve início o jogo entre os primos, o qual consistia na recusa da visão dos cadernos da menina mais velha pelo pequeno Canetti, alimentando sua inveja, que se transformou em tormento, prenúncio de uma ação desesperada do menino. Num dos dias de humilhação mati- 
nal, após o retorno da prima, esta lhe mostrara os cadernos com desdém, provocando-o 'Você é muito pequeno! Você ainda não pode ler!' [...]. Ele tentou pegar os cadernos, implorando que deixasse contemplar as letras, seu mais recente objeto de culto. Ela colocou os cadernos em cima do muro, ele, pequeno demais, não os alcançava. Enquanto ela ria desdenhosamente de seu desespero o menino pôs-se a correr em direção ao quintal. De lá voltou armado com um machado, disposto a matar a prima para obter os cadernos que guardavam as pequenas letras azuis. Se não houvesse ocorrido a intervenção de um adulto que, escutando o grito com que anunciava o assassínio da prima, em bom ladino, 'Agora vou matar a Laurica' [...] sua intenção de matar a prima com o pesado machado, talvez, tivesse se concretizado. (SOUZA, 2013, p. 196-197)

A sua mãe - vendo o desespero do garoto para compartilhar desta inscrição familiar, pois ler e escrever significavam muito numa comunidade como a dos sefarditas, cuja tradição e língua dependiam da precoce iniciação dos sujeitos à cultura, em seus aspectos mais letrados possiveis; ademais, num sentido mais nuclear, ler significava poder se relacionar com os pais, podendo compartilhar de seu mundo -, coube consolá-lo, dizendo que logo iria à escola, o que aconteceu, quando chagaram a Manchester, inaugurando a relação de nosso autor com este lugar: "na Inglaterra, eu iria logo à escola e aprenderia a ler e a escrever" (CANETTI, 2010a, p. 47). Mathilde Canetti não podia prever que essa relação, uma mistura de encantamento e desilusão, seria um dos motivos da ruptura entre mãe e filho, nem que os interesses do filho pela cultura letrada seriam mais fortes que pela escola, rivalizando sempre com o saber institucionalizado, cuja força não se assemelhava a todos os estímulos que o cercavam. Ele já estava na escola, só não tinha sido inscrito numa instituição, daí, talvez, venha sua relação reticente com todas as instituições escolares, preferindo retratar os sujei- tos às instituições - e nesse caso, é bom lembrar, trata-se do autor de Massa e poder (2011), que soube tão bem caracterizar os processos massivos institucionais; se o quisesse, teria caracterizado a escola como fenômeno social, sem maiores esforços.

\section{Entre professores e mestres}

A relação de Canetti com a escola não foi representada de maneira institucional, tal como nos acostumamos a nos referir no Ocidente “estudei na Escola [...]", "entrei para a Universidade [...]", "Terminei os estudos no Colégio [...]". Suas imagens são centradas nas relações com os professores das escolas pelas quais passou, salvo por uma ou outra descrição espacial, quando da mudança de prédio de uma escola para outra, quando aborda os colegas em sala ou quando menciona o laboratório de sua universidade. Além disso, nada mais sabemos sobre como foram essas escolas, em seus aspectos físicos ou administrativos, salvo obviedades, como o fato de sua escola ter uma direção (CANETTI, 2010a; 2010b).

Esta identificação, exceto pela indicação do ingresso no Realgymnasium (CANETTI, 2010a), quando dá alguma informação sobre as dimensões da instituição, é feita pela figura dos professores, dos quais pinta quadros que oscilam entre a crueldade e a ternura, reafirmando certo padrão de nosso autor, que, na abordagem de seus personagens, abusa do caráter, tal como em seu trabalho como romancista, em Auto-de-fé (1992). Assim, conforme sua própria convicção a respeito da construção de personagens, acentua a característica que sobra de um personagem, após a passagem do tempo, aquilo que permanece no que tem de mais forte, por isso, não é de se espantar que seus professores sejam apresentados de forma tão díspar: ou são maravilhosos ou terriveis, encantadores 
ou enfadonhos, dinâmicos ou preguiçosos. $E$ se os caracteres têm uma dupla função, a de servir de personagem e motivo para a autoanálise (CANETTI, 1989), ele abusa desta ambivalência, ao falar de seus professores e mestres escolares.

Mèlich (2010), tomando a distinção wittgensteiniana de signo e símbolo, presente no Tractatus (2001), procura estabelecer uma diferença ética entre a figura do professor e a do mestre; ${ }^{3}$ e ao contrastar estas imagens não o faz com o intuito de promover um antagonismo, e, mesmo que as vezes assim pareça, não deveria ser, pois são, antes, figuras complementares. Ele quer evidenciar a dimensão ética dessas inscrições, o dizer (do professor) e o mostrar (do mestre), como duas formas expressivas. 0 que se pode deduzir dessa diferenciação é que o mostrar, e o que ele acarreta - a ética, a estética e a religião - não pode se fundamentar no dizer, em uma teoria científica ou em uma demonstração, porque o que se pode mostrar não se pode demonstrar (MÈLI$\mathrm{CH}, 2010$ ).

Adotando esta perspectiva, o professor desenvolve um discurso lógico - pelo menos, pretensamente lógico -, e um discurso que também é informativo; por sua vez, o mestre não fala propriamente, ele mostra, e, por isso, sua forma de expressão é inspiradora, evocadora e sugestiva. "Enquanto a linguagem do professor é 'sígnica', a do mestre é 'simbólica"' (MÈLI$\mathrm{CH}, 2010$, p. 277). Por isso, o mestre se move no âmbito testemunhal, que não pode ser confundido com a apresentação de um exemplo. Sustentar que a forma expressiva do mestre é evocadora significa que o não dito se converte em uma forma intensa de comunicação.

30 termo mestre em português não consegue expressar o caráter reverencial e "orquestral" que a expressão maestro tem em espanhol, pois nomeia tanto aos professores de educação básica, pelas crianças, quanto na universidade, aos professores que se distinguem dos demais. É comum ouvir-se, em referência a um professor, que ele não é um professor, mas um maestro.
Este não-dito, o silêncio do mostrar, o silêncio místico, no caso do mestre, poderia fundamentar-se em três aspectos. Primeiro: o que pode ser mostrado não pode ser demonstrado. Segundo: o que pode ser mostrado não pode ser explicado. E, por derradeiro: o que pode ser mostrado não pode ser explicitado. (MÈLICH, 2010 , p. 277 , grifos do autor)

Diferente da relação professor-aluno, baseada na ideia de ensino e aprendizagem, a relação mestre-discípulo está baseada numa transmissão testemunhal, melhor dizendo, numa lição. Os professores não dão lições, estritamente, "e os que ainda o fazem deixarão de fazê-lo em breve, pois a lição não faz parte de seu manual de estilo. o professor, essencialmente, se limita a dar uma aula. Só o mestre dá uma lição" (MÈLICH, 2008, p. 2). A lição aqui entendida como dar a ler, uma dimensão pública de uma experiência de leitura, da leitura que atravessou o sujeito com a subjetividade do outro, dando-lhe acesso a outros mundos e experiências a partir do texto (LARROSA, 2000; 2003; SOUZA; CORDEIRO, 2015). O que o mestre transmite, melhor seria dizer, em português, inspira, não se pode demonstrar, explicar ou tornar explícito, pois não se pode reduzir a lógica da linguagem ao dito. Um sujeito pode inspirar o outro por vários gestos que não estão circunscritos ao que pode ser dito numa aula. Um mestre pode, não dizendo, dar importantes lições a seus discípulos. Um livro que se apresenta, um gesto de acolhimento, uma pergunta e até o convite para um café podem dizer mais que um semestre inteiro de aula, em alguns casos, mais que uma vida inteira de relações com a escola. Há coisas que não podem ser demonstradas, somente mostradas, sem que para isso virem exemplo, num sentido moral.

Assim como o bom cozinheiro não ensina a cozinhar (ou o amante não ensina a amar) dando um manual de instruções, o mestre não pode ensinar evidenciando, isto é, demonstrando ou 
explicando o que se quer ensinar. 0 mestre ensina ensinando o que não pode ser ensinado. ${ }^{4}$ O mestre mostra, dá testemunho. É então que o discípulo aprende, aprende 'por contágio', por mimese, e descobre o que o manual não pode ensinar, compreende o jogo de implícitos e de evocações ainda que, ao mesmo tempo, não possa torná-lo evidente. Como explicar a alguém o que é o gosto, o tato, a sensibilidade, a emoção? Como explicar em que consiste a compaixão? (MÈLICH, 2010, p. 279)

Os docentes de Canetti podem ser concebidos nesta dupla acepção, na medida em que este produz para eles caracteres bem indicativos de suas condições de mestres e professores. Muito antes da categorização melichiana, ele já havia sido afetado pelo que não pode ser dito e que somente pela inspiração se ensina. Seus professores e mestres são classificados por afecção, por aquilo que puderam ensinar, independente das aulas, das quais, por sinal, há pouco registro em toda a Trilogia Autobiográfica; a didática só aparece para ressaltar certo dito professoral que pouco significou para o autobiógrafo, foram demonstrações; ou para afirmar a condição magistral de outros.

Logo após sua chegada à Inglaterra, ingressou na escola de Miss Lancashire. Ele dá às suas escolas o nome de seus diretores e professores, as quais the ensinam o tratamento equitativo que a middle-class inglesa oferecia a seus cidadãos, com o desenvolvimento de práticas sociais comunitárias, para além da instrução (GOUVÊIA, 2013), e que colocavam todos, até o aristocrático menino de origem búlgara, na mesma condição dos demais.

Miss Lancashire era uma pessoa justa e tratava todas as crianças com a mesma amabilidade. Ela elogiava quando dizia alguma coisa em inglês fluente, pois esta de início era a minha desvantagem com relação às outras crianças. Mas logo aprendi a ler e a escrever e, quando

4 Esta frase brinca com os sentidos do verbo enseñar em espanhol, que designa tanto ensinar quanto mostrar. em casa comecei a ler os livros que meu pai me trazia, me dei conta de que ela nada queria saber disso. O que the importava era que todas as crianças se sentissem bem; os progressos rápidos nunca the interessavam. Jamais a vi nervosa ou zangada, era tão competente que nunca tinha dificuldades com as crianças. Seus movimentos eram seguros, mas não esportivos; sua voz era uniforme, nunca penetrante demais. Não me lembro de qualquer ordem sua. Certas coisas não eram permitidas; mas, como não se insistia nisso, nos submetíamos de boa vontade. Adorei a escola desde o princípio do dia. Miss Lancashire não era mordaz como nossa governanta e, sobretudo, não tinha o nariz pontudo. (CANETTI, 2010a, p. 57)

Após sua iniciação escolar na Inglaterra, segue com a mãe para numa viagem de retorno a Viena, para onde seguiram após a morte de seu pai. Aprende alemão durante a parada em Lausanne; inicia seus estudos na escola de outro professor, desta vez Herr Tegel, “que sempre repetia a mesma coisa e que, desde o começo, me parecera um tonto" (CANETTI, 2010a, p. 131). Descreve outra vez fisicamente o professor, desta vez sem a benevolência do desenho de Miss Lancashire: "Ele tinha uma cara gorda e vermelha, na qual pouco se podia ler, quase como uma máscara" (CANETTI, 2010a, p. 100). o professor duvida de seu aprendizado intensivo do alemão, submetendo-o a um teste expresso da língua teutônica, no qual se sai muito bem. Quando retorna para casa, a mãe the promete que pulará algumas classes, entrando para o ginásio, o que não será mais tão enfadonho para ele (CANETTI, 2010a, p. 101). As coisas mudam quando entra para o ginásio, em 1915 , mas nem por isso os professores passam a ser mais bem representados, era agora Herr Twrdy, um "anão gordo e barbudo" (CANETTI, 2010a, p. 131), professor de Latim, que "para eles [os colegas] repetia incansavelmente silva silvae" (CANETTI, 2010a, grifo do autor). Será em seu retorno à Suiça, para morar em Zurique, fugindo das consequências da Primeira 
Guerra sobre a capital austríaca, onde estava vivendo com sua mãe e irmãos, que encontrará uma miríade de professores e alguns mestres que the deixarão marcas profundas.

Inicialmente, a escola suiça trouxe-lhe preocupações. Suas virtudes e avanços em relação aos demais alunos vienenses de nada interessavam aos suiços; seus conhecimentos não seriam testados nem lhe colocariam em uma prova de nivelamento; não se faziam exceções e ainda duvidavam de sua capacidade, já que não se alfabetizara em alemão. Ele e a mãe temeram não encontrar uma escola que o acolhesse. Se em Viena havia pulado séries e se encontrava no segundo ano ginasial, na república helvécia deveria ser matriculado obedecendo à correlação idade-série. Os privilégios de classe a que estavam acostumados, aos quais somente o tratamento mais equitativo da escola inglesa the havia apresentado algum exemplo de uma sociedade menos aristocrática, agora se materializava como realidade, não havia quem the concedesse privilégio algum.

[as escolas suiças] Atinham-se rigorosamente à idade, e, onde que eu aparecesse com minha mãe para requerer minha matrícula, recebíamos a mesma resposta. Minha mãe não previra que por causa de nossa vinda à Suiça, eu perderia um ano ou mais, e não se conformava com a ideia. Tentamos em toda parte, até mesmo chegamos a viajar a Berna. A resposta curta e decidida, era sempre a mesma e, como não vinha acompanhada do 'minha senhora' e outras gentilezas vienenses, parecia-nos ainda mais rudes. Sempre que vínhamos de mais uma visita a um desses diretores, minha mãe se desesperara. 'O senhor não quer examiná-lo', ela implorava. 'Ele está adiantado para a sua idade'. Mas era justamente isso que eles não gostavam de ouvir: 'Não fazemos exceções'. (CANETTI, 2010a, p. 169)

Ao retornar ao ensino do primário, sente-se rebaixado de tal forma que passa a se ocupar com quantas vezes e com quais entonações ou sotaques os colegas eram chamados pelo professor, Herr Bachmann, em sala de aula. Foi ao mudar de escola, deixando a periférica escola em Oberstrass, para estudar na escola cantonesa de Rämistrasse, que encontra seus primeiros mestres (CANETTI, 2010a).

Nesse momento, os professores passam a ser categorizados com maior cuidado. Ele se surpreende com a diversidade de professores, que acredita ser a primeira diversidade a que é apresentado na vida (CANETTI, 2010a). A leitu$\mathrm{ra}$, antes uma forma de se relacionar com o conhecimento fora da escola, encontra em Eugen Müller uma provocação para se perceber que na escola também poderia se fruir a leitura tal como em casa.

As aulas de Eugen Müller invariavelmente produziam em mim esse efeito. Quando nos falava dos gregos, seus olhos, abertos descomensuradamente, parecia-me os de um vidente extasiado; ele nem sequer olhava para nós, mas para aquilo de que falava; sua fala não era rápida, mas ininterrupta, ao ritmo das ondas do mar; quer a luta fosse em terra, quer fosse na água, eu sempre me sentia em meio ao oceano. Passava as pontas dos dedos sobre a testa levemente coberta de suor; mais raramente, passava a mão sobre o cabelo encrespado, como se soprasse uma brisa. Nesse absorvente entusiasmo transcorria a hora; quando tomava ar para novo alento, era como se bebesse. (CANETTI, 2010a, p. 184)

Seu encantamento com Müller o fazia entender as atividades avaliativas como uma perda de tempo, pois estas lhe retiravam os momentos de relação, de transformação da aula em uma experiência de si, "elaboração ou reelaboração de alguma forma reflexiva do sujeito consigo mesmo" (LARROSA, 1999, p. 36), o que imprime outra dimensão do cuidado de si ao sujeito, como condição de acesso à verdade, ao compartilhar o conhecimento de si mesmo com o outro, com o espírito do outro, consumado por certa transformação do sujeito (FOUCAULT, 2011). Tudo o que não era relação 
intelectual, os trabalhos práticos em classe, em seu sentido estrito, eram rejeitados.

Às vezes, no entanto, perdíamos tempo, e isso quando ele nos tomava a lição. Mandava que escrevêssemos redações e as discutia conosco. Então lamentávamos cada momento perdido, que de outro modo passaríamos com ele ao mar. Muitas vezes eu me apresentava para responder às suas perguntas, não só para que isso acabasse logo, mas também para lhe demonstrar o meu apreço por cada uma de suas frases. Minhas palavras podem ter soado como a prolongação de seu próprio entusiasmo, podendo ter aborrecido meus colegas, alguns dos quais eram bem lerdos. Não tinham vivido sob um império; para eles a liberdade grega não podia ter o mesmo significado. A liberdade lhes era natural e não precisava ser conquistada por intermédio dos gregos. (CANETTI, 2010a, p. 184-185)

\section{À Eugen Müller reputa tamanha considera-} ção que compara suas aulas à leitura de um livro. Nesses momentos, a escola lhe dava o que em outro espaço somente os livros eram capazes, e Herr Müller, o melhor exemplar dessa biblioteca, se destacava por sua capacidade de fascinar os sujeitos com sua narrativa: “já por causa de sua matéria, estava obrigado a possuir alto grau de entusiasmo e talento narrativo, mas tinha algo que ultrapassava em muito aquilo que the era exigido. Assim, ele me conquistou desde a primeira lição, e eu contava os dias da semana pelas suas aulas" (CANETTI, 2010a, p. 185).

Contrastavam com esta representação do professor magistral as caracterizações dos professores Hunziker e Billeter, classificados, respectivamente, como tedioso e enfadonho. Num sentido melichiano (2007), davam explicações, apresentavam alguns axiomas e através de algum roteiro chegavam a algumas conclusões, eram propriamente professores.

Fritz Hunziker, o professor de alemão, tinha mais dificuldades; era, de natureza, um pouco lacônico, talvez prejudicado por sua figura não muito harmoniosa, cujo efeito não era atenuado por sua voz um tanto rangente. [...] Não massacrava ninguém, mas também não inspirava ninguém; sua proteção era um sorriso irônico, ao qual ele se atinha, e que não desaparecia mesmo quando já parecia inadequado. Seus conhecimentos eram equilibrados, talvez um pouco classificados demais; de qualquer forma não nos arrebatava, mas também não nos desorientava. (CANETTI, 2010a, p. 185)

Gustav Billeter, o professor de latim, [...] falava com fluência e suavidade, a voz um pouco baixa, sem excitação desnecessária; quando se zangava, para o que às vezes não lhe faltava motivo, ele não levantava a voz, apenas falava um pouco mais rápido. As bases elementares do latim, que ele nos ensinava, certamente eram enfadonhas, e talvez também por isso toda a sua atitude fosse tão humana. (CANETTI, 2010a, p. 186)

Canetti nos apresenta uma escola na qual é possivel o estudo do outro, pelo qual desenvolvemos as primeiras relações com a diversidade. A diferença inscrita na diversidade canettiana é que, para ele, mais uma vez, seus professores são caracteres de uma taxonomia, tal como nas categorizações dos grupos de animais ou em sua compilação de caracteres (CANETTI, 1989).

A multiplicidade dos professores era surpreendente; é a primeira diversidade de que se é consciente na vida. Que eles ficassem por tanto tempo parados à nossa frente, expostos em cada um de seus movimentos, sob incessante observação, hora após hora o verdadeiro objeto de nosso interesse, sem poderem se afastar durante um tempo precisamente delimitado; a sua superioridade, que não queremos reconhecer de uma vez por todas e que nos torna perspicazes, críticos e maliciosos; a necessidade de acompanhá-los sem que queiramos nos esforçar demais, pois ainda não nos tornamos trabalhadores dedicados e exclusivos; também o mistério que envolve sua vida fora da escola, quando não estão à nossa frente como atores, representando a si próprios; e, mais ainda, a alternância dos personagens, um após outro, no mesmo papel, no mesmo lugar e com a mesma 
intenção, portanto eminentemente comparáveis - tudo isso, em seu efeito conjunto, é outra escola, bem diferente da escola formal, uma escola que ensina a diversidade dos seres humanos; se a tomarmos um pouco a sério, resulta a primeira escola em que conscientemente estudamos o homem.

Não seria difícil, e talvez fosse interessante, analisar a própria vida, em busca de saber quantos e quais desses professores foram reencontrados sob outros nomes, quais nos foram simpáticos por causa disso, de quais nos afastamos só por causa de uma velha antipatia, quais as decisões tomadas devido a um antigo conhecimento, o que teríamos feito diferente, sem tal conhecimento. À primeira tipologia infantil, baseada nos animais e que conserva sua eficácia, é sobreposta uma nova tipologia, a dos professores.

Agora, quando os faço desfilar diante de mim, admiro-me da diversidade, da peculiaridade, da riqueza de meus professores de Zurique. De muitos deles aprendi tudo aquilo que correspondia às suas intenções, e a gratidão que por eles sinto após cinquenta anos, por estranho que possa parecer, se torna maior a cada dia que passa. Mas também aqueles de quem pouco aprendi estão nitidamente à minha frente como pessoas ou como figuras, que só por isso me sinto em dívida com eles. [...] A interpretação da fluidez que existe entre indivíduos e tipos é, verdadeiramente, uma das tarefas do escritor. (CANETTI, 2010a, p. 187-188)

Ele desejava fazer parte deste mundo, não necessariamente como professor, mas como alguém que se media pelos professores e via em suas atuações uma autorização para a exposição de suas ideias ao público. “Eu me portava perante o professor como se ele fosse minha mãe" (CANETTI, 2010a, p. 255), o que significava que sua conduta em sala era de provocação aberta e irrestrita, e, como ele mesmo diz, a única diferença entre seu comportamento combativo, em casa e na escola, era que nesta última precisava levantar o dedo antes de responder. Enquanto uns professores se sentiam acolhidos pela sua participação e entendiam a intervenção do aluno como um atestado do bom desenvolvimento de suas ideias, pois, se estava se colocando, deveria ser porque estava entendendo a aula; outros se preocupavam com a equidade e temiam, ao autorizar a participação, que os alunos não participativos - lentos, na linguagem da autobiografia canettiana - fossem prejudicados. Esses professores o viam como um mal. Para ele, e falando em nome de um jovem que provavelmente é ele, há em cada aluno um Heródoto - num sentido universalista, de formação ampla e humanista - e tentar treiná-lo, para que ocupe uma profissão na sociedade, é uma espécie de crime que a escolarização promove diariamente (CANETTI, 2010a).

Pois bem, a parte essencial da vida de um ser que começa a tomar conhecimento passa-se na escola, a primeira experiência pública de um jovem. Este poderá procurar distinguir-se, porém, muito mais do que isso, procurará irradiar o saber tão logo o conquiste, para que não seja uma mera posse. Os colegas mais lentos pensarão que tal jovem quer insinuar-se junto aos professores e o considerarão ambicioso. Mas ele não tem em vista um alvo a alcançar, pois quer ultrapassar tais alvos e envolver seus professores em sua ânsia de liberdade. Ele não se mede pelos colegas, mas pelos professores. Sonha em expulsar deles todo o utilitarismo, quer sobrepujá-los. Só ama, com um amor efusivo, aqueles professores que não se renderam a fins práticos, que querem irradiar seu saber pelo próprio saber - a estes presta homenagem com suas reações rápidas, a estes é constantemente grato pela inesgotável transmissão de seu saber. (CANETTI, 2010a, p. 256-257)

Aos professores dedica um capítulo de natureza taxonômica, A chegada dos animais (CANETTI, 2010a), no qual descreve cada um de seus professores ginasiais, oscilando entre as imagens de professor e mestre. A começar por Karl Beck, quem deixava deslizar, entre o conteúdo e sua atuação, muito mais do que poderia dizer. 
Karl Beck era um professor como todos o desejam, enérgico e brilhante. Entrava na sala de aula com a rapidez do vento, se colocava a nossa frente, não perdia tempo e entrava em cheio no tema. Era empertigado e magro, mantendose ereto sem qualquer sinal de rigidez. Seria pela indole da matéria que suas aulas transcorriam sem quaisquer complicações pessoais? Sua matemática era clara e se dirigia a cada um de nós. Ele não fazia distinção entre os alunos, cada um existia por direito próprio. Mas se alegrava abertamente quando havia bom aproveitamento; tinha uma maneira de demonstrá-lo que não era tomada como favoritismo, assim como suas decepções não demonstravam preterição [...] Não era daqueles que nos conquistavam por sua calidez, mas antes por una espécie de destemor. Ele não procurava nos agradar, tampouco nos oprimia [...] Deve ter sido um homem de espírito crítico, o que reconheço agora, quando me lembro dele: a distância que mantinha era intelectual. Não procurava se impor por sua importância, como os professores tendem a fazer, mas por sua constante vitalidade e clareza. A classe tampouco o temia e, de início, tentou meter-se com ele. Certa vez o recebeu com gritaria. Ele já estava junto à porta aberta e a classe continuava a berrar. Ele olhou para aquilo por alguns momentos, zangado: 'Não vou dar aula!', bateu a porta atrás de si e desapareceu. Não houve castigo, nem julgamento, nem investigação; ele simplesmente não estava lá. A classe ficou sozinha com sua gritaria, e o que a princípio pareceu uma vitória acabou ficando ridículo e se apagou. (CANETTI, 2010a, p. 280)

Aquilo que só pode ser mostrado, não pode ser dito, nem explicado, mas encontra na performance, no ato, o poder de ressonar nos sujeitos como uma lição, que aponta para uma aprendizagem simbólica do corpo, que conversa sem dizer. Viver é interpretar o mundo, a partir do próprio corpo, através de um simbolismo que se constrói em função de uma tradição sempre aberta à mudança e à novidade (BÁRCENA; MÈLICH, 2000). 0 eu, simbolizado no corpo, dialoga com os sentidos dos outros corpos. Ao se pensar a escola, para além de uma relação subscrita ao que pode ser dito, mas como um espaço no qual dialogam silêncios, não ditos, gestos, atitudes, estes movimentos atuam sobre os sujeitos com uma força que não se pode programar. Essa incerteza abre muitas possibilidades formativas, nos interstícios, ou nos vazios do planejamento, dos planos e dos projetos. 0 que não pode ser planejado emerge como possibilidade de investigação, por parte do sujeito que aprende, curioso, e se põe a perscrutar aquele outro que se expõe diariamente à sua frente. Canetti (2010a), ao apresentar seus professores, nos dá importantes exemplos de que, ademais do programa, todos os professores, em sua atuação, oferecem muito mais do que aquilo a que se propõem, por vezes, involuntariamente. Seus corpos podem ser espaços de hospitalidade, de acolhimento ao recém-chegado e àquele que se forma - dando à educação um caráter radicalmente ético e poético; mas também podem ser espaços de repulsa, sob domínios discursivos predeterminados, com objetivos rígidos e pouco abertos ao diálogo (DUCH; MÈLICH, 2012; MÈLICH, 2000).

Outro tipo de professor que ele experimenta na escola, o professor-autor, erige-se como um animal especial, do tipo que se toma contato, antes mesmo de encontrá-lo em sala de aula. Seu fascínio pelo professor-autor traz certa expectativa, que depositava nos intelectuais de maneira geral, desejando um dia se colocar nesse lugar, só que, nesse caso, os professores são retratados como figuras menos radiantes que os intelectuais que conhecera fora da escola.

Nosso livro de geografia era de autoria de Emil Letsch, a quem também tínhamos como professor. Eu conhecia o livro antes que ele viesse a nossa classe; quase o sabia de cor, pois continha muitos números. A altura das montanhas, o comprimento dos rios, a população dos países, cantões e cidades - tudo o que se podia expressar em algarismos eu tinha gravado, e ainda hoje sofro com esses números, quase to- 
dos defasados. Eu levava muita fé no autor de tal plenitude; quem havia escrito um livro para mim era uma espécie de Deus. Ficou evidente, porém, que esse autor, de Deus, só tinha a ira e nada mais. Letch comandava mais do que ensinava, e para cada objeto que mencionava ele acrescentava o preço. Era tão severo que não riu, ou sequer sorriu, uma única vez. Fiquei logo enfadado dele, porque nada dizia que já não estivesse escrito em seu livro. Era exageradamente sucinto, e esperava de nós a mesma concisão. As más notas choviam sobre a classe como bordoadas. Ele era odiado, mas tanto, que esse ódio, para muitos de seus alunos ficou sendo a única lembrança dele. (CANETTI, 2010a, p. 280-281)

Ao professor Emil Walder, também autor de livro didático, dedicou um tratamento mais reverencial.

Emil Walder, o idoso, era autor da gramática na qual estudávamos latim; era o único autor de um livro didático, à parte Letsch, que tive como professor na escola cantonal. Eu o aguardava com a curiosidade e o respeito que dedicava a todo autor. [...] Como eu tinha facilidade em aprender latim, acostumei-me a levar com ele uma espécie de vida dupla. Com os ouvidos seguia suas explicações, de modo que eu sempre sabia responder quando era chamado. Com os olhos lia um pequeno volume que mantinha aberto debaixo da carteira. Mas ele era curioso, tirava-o de lá de baixo quando passava por mim, levava-o bem próximo aos olhos até ver do que se tratava, e o devolvia para mim, ainda aberto. Quando nada dizia, supunha que aprovava minha leitura. Deve ter sido leitor um leitor assíduo. (CANETTI, 2010a, p. 292-293)

Já o professor Fenner o cativou, não apenas por ter aulas bem planejadas e profundas, mas por tratar de assunto ignorado em sua casa, e pelo qual sua mãe nutria certa indiferença, a História Natural.

Tenho melhores notícias de Karl Fenner, o professor de história natural. Aqui perco de vista o homem, dentro da imensidão da paisagem que ele me desvendou. [...] Ele nos explicava, com infinita paciência, a estrutura das plantas e dos animais. Incumbia-nos de fazer desenhos coloridos, os quais executávamos em casa com todo esmero. Ele não se satisfazia facilmente com esses desenhos, mencionando cada um de nossos erros, insistindo com suavidade, mas obstinado, em que melhorássemos; a mim ele aconselhou várias vezes que jogasse fora tudo e tentasse novamente. [...] mas suas aulas eram objetivas e bem planejadas, e de uma profundeza que dava gosto; nós progredíamos devagar, mas o que ele nos ensinava não se esquecia, ficava gravado pra sempre. [...] Ele fazia excursões conosco, e todos gostávamos disso. O ambiente, então, era alegre e descontraído; nada era omitido. No lago Rumen recolhíamos toda espécie de pequenas criaturas aquáticas, que levávamos para a escola. Ele nos mostrava, no microscópio, essa vida fantástica que havia em minúsculo espaço, e tudo que víamos era depois desenhado. Preciso conter-me para não entrar em detalhes e passar a ministrar um curso de história natural, o que não posso impor aos leitores, por suposto, já conhecem a matéria. (CANETTI, 2010a, p. 282-285)

De todos estes professores, no entanto, foi um jovem substituto, que reencontrará décadas mais tarde, como apresentador de um programa de rádio (CANETTI, 2013), e que o cativou, sendo o segundo amor de seus anos escolares - o primeiro havia sido Müller, o grego - "um homem que jamais esqueci e que reencontrei muitos anos depois quase o mesmo" (CANETTI, 2010a, p. 294).

[Witz lhe pergunta se recorda dele] Bom, recordar é uma palavra muito débil para isso. Pois nunca deixei de lamentar, meu querido doutor Witz, que não fosse o senhor meu professor por mais tempo. Suas aulas eram uma alegria constante. Havia nessas aulas uma liberdade que só podia descrever empregando para isso um extenso capítulo de um romance [este diálogo ocorreu em 1968, é anterior a escrita de A Língua Absolvida, no qual Witz aparece retratado]. Com o senhor, a História estava sempre imersa em uma atmosfera literária. Recordo que quando nos falou dos Hohenstaufen nos leu logo em seguida, com incrivel vitalidade, um drama inteiro de Liliencron. E nas excursões escolares o 
senhor nos falava de tudo que podia ser imaginado. Recordo, por exemplo, que foi a primeira pessoa de quem ouvi mencionar Morgenstern. 0 senhor era um professor muito jovem à épo$\mathrm{ca}$, acredito que sua verdadeira carreira começou depois; por isso penso, às vezes, que talvez o senhor não compreenda o valor que essas aulas significaram para mim na ocasião. Sinceramente, considero possivel que sem o senhor fosse outra pessoa. (CANETTI, 2013, p. 727-728)

O professor que o marcou de forma tão indelével, Friedrich Witz, não se investia da posição de professor, oscilava entre o púlpito e os alunos, com entusiasmo, aos quais não fazia distinção. Tudo o que dizia parecia, aos olhos do jovem Elias, uma novidade, apesar de ser História, a mesma História com a qual já havia tido contato, agora era apresentada como uma narrativa. "Não era um ensino rígido, ele nos dava aquilo de que ele próprio estava imbuído [...] No fundo só the importavam os escritores, com os quais ele nos confrontava em todas as ocasiões [...] Não admira que Witz se tornasse, de imediato, meu ideal [...] como um amigo" (CANETTI, 2010a, p. 293). O gesto da informalidade aproximava alunos e professor.

Sua relação com a disciplina era feita conjuntamente com a literatura. Não se pode relacionar esta abordagem com nenhuma corrente histórica da época - nem a Escola dos Annales, que inseriu a possibilidade de relativização do discurso histórico e da "verdade" histórica, existia enquanto projeto, muito menos sua vertente cultural, que a aproximou da narrativa literária, e propõe o uso da literatura como fonte da escrita e do ensino de história, marcados, à época, como ainda hoje, pela historiografia rankeana - "Tínhamos chegado à história dos Hohenstaufen; em vez de datas nos oferecia imagens" (CANETTI, 2010a, p. 295). A abordagem de Witz, avant la lettre, antecipou em anos qualquer iniciativa coordenada interdisciplinar de aproximação da história a outros campos de conhecimento - a narrati- va na qual se insere o capítulo $A$ chegada dos animais ocorre entre 1916 e 1919. Sua história cultural intuitiva fascinou o jovem Canetti, que vivia num mundo marcado pelas leituras do passado, por uma noção de literatura universal, da qual o autor de publicação mais recente era Strindberg, sob a direta influência e orientação materna. O professor não apenas o cativa com uma aula de história, apresenta-lhe a literatura de seu tempo presente.

Já disse que Witz me abriu os olhos para a literatura moderna, viva. Quando ele mencionava, eu jamais o esquecia; tornava-se parte de minha própria atmosfera, à qual ele me levava consigo, e as asas que me pôs para esses voos, sem que eu o notasse, ficaram comigo mesmo depois que ele me deixou, e agora eu empreendia meus próprios voos, olhando, surpreso, ao meu redor.

Resisto em mencionar individualmente todos os nomes que, através dele, me impressionaram. Alguns deles eu já ouvira antes, sem que me tocassem, como Spitteler; outros haviam despertado apenas uma curiosidade passiva, como se bastasse mantê-los de prontidão para mais tarde, como Wedekind. A maioria deles hoje faz parte, com tanta naturalidade, da literatura corrente, que parece ridículo fazer alarde em torno disso. Mas a maior parte, que aqui deixo de mencionar, formava um contraste muito forte com o que eu trouxera de casa, e, embora eu tivesse me apropriado de pouquíssimo daquilo, o preconceito contra os que tinham morrido havia pouco, ou que ainda estavam vivos, fora quebrado de uma vez por todas. (CANETTI, 2010a, p. 298)

Não é de se imaginar que as aulas livres do professor Witz passassem despercebidas ou que fossem unanimidade entre seus colegas. Estes últimos, a grande maioria, resistiam a suas aulas, vendo na liberdade e na interdisciplinaridade, uma espécie de caos, especialmente pela recusa de Witz em se impor sobre os alunos, admoestando-os. Chegou a sofrer a intervenção de colegas mais velhos, que apre- 
sentavam relatórios de suas aulas à direção. o professor era um pouco mais velho que os alunos, um recém-formado. Ele compara o professor a um livro, não um livro de matemática, como o professor Karl Beck, linear, com um caminho seguro que não permite que se olhe para a direita ou para a esquerda, muito menos que se desvie; era um livro do tipo que lhe apresenta o gosto pela transformação.

Tocava-me em muitos pontos, ainda obscuros para mim, ao mesmo tempo, e eles se iluminavam sem qualquer objetivo. Não se caminhava para frente, mas estava-se ora aqui, ora acolá; não se tinha um alvo em mira, nem sequer uma meta desconhecida; é certo que se recebia muitas informações, mas, mais do que ser informado, adquiria-se uma sensibilidade para aquilo que fora descartado ou para o que ainda permanecia oculto. Ele fortalecia, sobretudo, o gosto pela transformação: quanta coisa existia de que não se tinha ideia, e bastava que a gente ouvisse falar naquilo, para que se tornasse aquilo. Era o mesmo que por mim, antigamente, haviam feito os contos de fadas, só que agora se tratava de outros objetos, menos simples de figuras, por certo, mas agora essas figuras eram os autores. (CANETTI, 2010a, p. 297-298)

Um dia, quando voltavam de uma aula de campo, teve a oportunidade de conversar com o professor, fez-lhe perguntas pessoais e as respostas converteram-se para ele em uma espécie de mantra religioso, muito particular. Este lhe falou sobre a vontade e o desespero, sobre não saber o que fazer de sua vida e de que só lhe restava uma certeza, a instabilidade. Estas respostas deixaram Canetti inseguro, "maravilhosamente confuso" (CANETTI, 2010a, p. 303), pois quem ele seguia não sabia para onde estava indo. Witz lhe dá uma lição sobre a incerteza, a sabedoria de um saber incerto e em constante transformação, uma transformação ambígua e transgressora (MÈLICH, 2003).

Após a experiência da diversidade, todos os espaços escolares por onde passou, em comparação, parecem vazios e sem sentido.
Agora a escola é nomeada, sem a identificação com um professor, tal como ocorrera até o momento em sua narrativa: na Escola Wholer em Frankfurt, que, diferente de sua experiência em Zurique, onde os professores mereciam nota individualizada, começa por sentenciar sua relação com o corpo docente: “Aos professores da escola, com uma única exceção, nunca pude me afeiçoar" (CANETTI, 2010b, p. 51):

O colérico professor de Latim perdia a compostura à menor provocação, e então os insultava, chamando-nos de burros fedorentos. E este não era seu único insulto. Seu método de ensino, baseado em sentenças modelo que tínhamos de recitar, era ridículo. Era espantoso que minha aversão por ele não me fizesse esquecer o Latim que eu aprendera em Zurique. Jamais, em qualquer outra escola, presenciei acessos de fúria tão desagradáveis e ruidosos quanto os dele. (CANETTI, 2010b, p. 51)

Dentre esses professores havia um que conseguia se destacar da massa, Gerber, o professor de alemão. Não era um professor do tipo estimulante, mas alguém que procurava compreender os alunos e, diferente dos outros professores, não era autoritário nem procurava um tom viril, para se afirmar diante do grupo de alunos adolescentes.

[...] desejo falar de um homem calmo e distinto, ao qual devo agradecimentos. Gerber era nosso professor de alemão; em contraste com os outros, parecia quase tímido. Através das composições, cujos temas ele nos apresentava, desenvolveu-se entre nós uma espécie de amizade. No começo, essas composições me enfastiavam, quer se tratasse de Maria Stuart ou de algo semelhante; mas elas não me exigiam esforço e ele se dava por satisfeito com tudo o que eu fazia. Depois os temas se tornaram mais interessantes e eu passei a manifestar minhas verdadeiras opiniões, as quais, em relação à escola, eram bastante rebeldes e, certamente, não correspondiam às suas próprias. Ele, contudo, deixava-as passar; escrevia com tinta vermelha, no final, longas observações nas quais me dava motivos para refletir. Ao mesmo tempo 
em que era tolerante, não poupava elogios à maneira pela qual expunha meu ponto de vista. (CANETTI, 2010b, p. 52)

Um gesto desse professor, no entanto, permitiu-lhe completar seus estudos para além da sala de aula. Gerber era o administrador da biblioteca do corpo docente e permitiu a Elias que levasse tudo o que queria ler. Canetti tratou de aproveitar a ocasião, para ampliar seu conhecimento dos gregos, dos quais leu tudo que pôde, dos dramas aos historiadores, só negligenciando os filósofos.

Após terminar o ensino secundário, inicia seus estudos superiores na Universidade de Viena, curiosamente, na Faculdade de Química, disciplina cuja experiência na educação secundária foi um desastre e afirmava não ter aprendido nada. Assim, na universidade, poderia se ilustrar um pouco no campo de conhecimento para o qual se sentia malformado: "Eu havia resolvido iniciar, em Viena, meus estudos de química (sem ter certeza de que persistiria) [...] Como eu nada havia aprendido dessa matéria na escola em Frankfurt, já era tempo que adquirisse algumas noções" (CANETTI, 2010b, p. 61). E compara o professor de química do ensino secundário, mais uma vez, a um animal:

É verdade que eu tinha um ou outro mau professor, que nada nos transmitia, absolutamente nada, e ainda nos enchia de aversão por sua matéria. Um professor desses fora, em Frankfurt, o de química. Pouco me sobrou de suas aulas. Além das fórmulas da água e do ácido sulfúrico e seus movimentos, durante as poucas experiências que ele nos demonstrou, me enchiam de repugnância. Era como se à nossa frente estivesse sentada uma preguiça disfarçada. (CANETTI, 2010b, p. 114)

Não encontra na universidade um corpo docente digno de menção, dedica-se a falar da falta de sentido do trabalho universitário, de como seu tempo produtivo era gasto em atividades manuais e laboratoriais, que não o desafiavam, além de declarar ter aberto raramente um livro de química ou seus cadernos de estudo, que ficavam estrategicamente dispostos na mesa de trabalho, em casa, como se estivessem ali para serem utilizados, muito prontamente, mesmo que nunca os abrisse. $\mathrm{Na}$ universidade limitava-se ao mínimo.

Não houve um instante sequer em que eu pretendesse seriamente trabalhar algum dia como químico. Eu frequentava o laboratório, lá passava a maior parte do dia; fazia o que era exigido, não de forma pior que os outros. Inventei uma motivação própria para justificar essa atividade perante mim mesmo. Eu ainda alimentava o desejo de saber e me apropriar de tudo o que valia a pena conhecer no mundo. Ainda tinha a crença inabalável de que isso era conveniente e também possível. Não via limitações em parte alguma, nem na capacidade de apreensão de um cérebro humano, nem na natureza monstruosa de uma criatura que consistia em nada mais do que aquilo que apreendera e na intenção de continuar apreendendo. Além disso, eu ainda não havia descoberto qualquer conhecimento a cuja aquisição me dedicasse que me fosse inacessivel. (CANETTI, 2010b, p. 114)

o único professor universitário que menciona em todo o seu ensino de graduação e doutoramento é Hermann Frei, muito mais por sua atitude equitativa para com os judeus, incluindo em sua aula os recém-chegados da Galícia Oriental, do que por seu trabalho, que é descrito como um homem com estrito sentido de ordem, do tipo feito para o trabalho quantitativo, o que não é necessariamente um elogio.

Não dá informação alguma sobre seu ingresso no doutorado nem sobre seu objeto de tese e diz que só segue fazendo por já ter começado. "Aparentemente eu continuava a estudar química, e comecei a trabalhar em minha tese; mas a tarefa que me coube era tão pouco interessante, que não chegava a atingir a parte mais superficial de meu intelecto" (CANETTI, 2010b, p. 252). Aproveitava seu tempo com outras coisas, qualquer uma que the in- 
teressasse. "Eu vivia tão à margem da química que não posso pensar naquele tempo sem que me ocorram rostos e conversas que com ela nada têm a ver" (CANETTI, 2010b, p. 257). Em setembro de 1929, aos 24 anos de idade, conclui sua tese de doutoramento sobre álcool amílico: "E com isso concluí um curso que me servia de adiamento e, afora disso, nada significava" (CANETTI, 2010b, p. 309), e do qual the restou uma pálida recordação da falta de sentido da escolarização universitária:

[...] e logo eu estava passando defronte ao Instituto de Química, onde desperdiçara alguns anos, sem qualquer propósito ou proveito [...] Ficava aliviado ao pensar que escapara dali; ligeiro, o bonde deixava o Instituto para trás, repetindo minha fuga, a qual eu não me cansava de abençoar. Quão rapidamente podemos olhar novamente o passado, e com que alegria revivemos nossa salvação dele! (CANETTI, 2010c, p. 292, grifos nossos)

As relações de Canetti com seus professores, longe de serem experiências únicas, parecem se repetir onde quer que o espaço escolar se reproduza. Muitos dos animais canettianos encontram-se agora diante de seus alunos,

\section{REFERÊNCIAS}

ARAUJO, E. S. Da(r) vida à formação, da(r) formação à vida. Série Estudos - Periódico do Mestrado em Educação da UCDB, n. 17, p. 43-51, 2004. Disponível em: <http://www.serie-estudos.ucdb.br/index.php/ serie-estudos/article/view/491>. Acesso em: 01 nov. 2015.

BÁRCENA, F; MÈLICH, J-C. El aprendizaje simbólico del cuerpo. Revista Complutense de Educación, v. 11, n. 2, p. 59-81, 2000. Disponivel em: <http://www. farq.edu.uy/cursillo/files/2013/07/17832-17908-1PB.pdf>. Acesso em: 30 mai. 2014.

CANETTI, E. Arrebatos verbales: dramas, ensayos, discursos y conversaciones. Tradução de Juan José del Solar, Adan Kovacsics, Carlos Fortea e "experimentando" dar aula e, dessa forma, afetando os alunos com muito mais do que o conteúdo escolar programado pelas instâncias administrativas da educação e pelas dosagens prescritivas dos livros didáticos. Nós, os autores deste texto - e provavelmente muitos dos leitores que a ele chegarem -, somos um desses animais e nos vemos em muitos dos docentes, professores e mestres, retratados pelo jovem búlgaro.

Podemos ver também muitos dos professores que tivemos, melichianamente falando, e temos, na vida, mais professores que mestres, pois acreditamos que esta seja a tônica para todos nós, haja vista que é muito maior o número de pessoas ocupadas com a repetição de processos arbitrários, em nossas escolas, do que sujeitos que nos inspirem. Talvez seja um problema formativo, como nos diz Larrosa (2015), nossos alunos universitários estão sempre querendo tirar a disciplina da frente, uma nota melhor, preocupam-se com avaliações e créditos. Esses sujeitos, depois de concluídos os seus estudos, serão professores, vão "professar" o que aprenderam. E aprenderam o quê?

José Manuel de Prada Samper. Barcelona: Debolsillo, 2013.

CANETTI, E. A língua absolvida: história de uma juventude. Tradução de Kurt Jahn. São Paulo: Companhia das Letras, 2010a.

CANETTI, E. Uma luz em meu ouvido: história de uma vida 1921-1931. Tradução de Kurt Jahn. São Paulo: Companhia das Letras, 2010b.

CANETTI, E. 0 jogo dos olhos: história de uma vida 1931-1937. Tradução de Sérgio Tellaroli. São Paulo: Companhia das Letras, $2010 \mathrm{c}$.

CANETTI, E. Massa e poder. Tradução de Sérgio Tellaroli. São Paulo: Companhia das Letras, 2011. 
CANETTI, E. O todo-ouvidos. Cinquenta caracteres. Tradução de Herbert Caro. Rio de Janeiro: Espaço e Tempo, 1989.

CANETTI, E. Auto-de-fé. Tradução de Herbert Caro. Rio de Janeiro: Nova Fronteira, 1992.

CATANI, D. B. Pedagogia e museificação. Revista USP, n. 8, p. 23-26, dez./jan./fev. 1990-1991.

CATANI, D. B.; BUENO, B. A. O.; SOUSA, C. P. de. O amor dos começos: por uma história das relações com a escola. Cadernos de Pesquisas, n. 111, p. 151-171, dez. 2000. Disponível em: <http://www.scielo.br/pdf/cp/ n111/n111a08.pdf>. Acesso em: 20 nov. 2012.

DUCH, L. L.; MÈLICH, J-C. Escenarios de la corporeidad. Tradução de Enrique Anrubia Aparici. Barcelona: Editorial Trotta, 2012.

FOUCAULT, M. A hermenêutica do sujeito: curso dado no Collège de France (1981-1982). Tradução de Marcio Alves da Fonseca e Salma Tannus Muchail. São Paulo: Martins Fontes, 2011.

GOUVÊIA, M. C. S. Escola compulsória inglesa: história e historiografia. Revista Brasileira de Educação, v. 18, n. 53, p. 377- 396, 2013. Disponivel em: <http://www.scielo.br/scielo.php?pi-

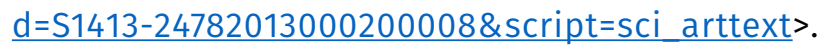
Acesso em: 28 out. 2015.

LARROSA, J. Tecnologias do eu e educação. In: SILVA, T. T. (Org.). 0 sujeito da educação: estudos foucaultianos. Petrópolis, RJ: Vozes, 1999. p. 35-86.

LARROSA, J. Pedagogia profana: estudios sobre lenguaje, subjetividad y formación. Buenos Aires: Ediciones Novedades Educativas, 2000.

LARROSA, J. Literatura, experiencia y formación. In: LARROSA, J. La experiencia de la lectura: estudios sobre literatura y formación. México: FCE, 2003. p. 25-54.

LARROSA, J. Tremores: escritos sobre experiência. Tradução de Cristina Antunes e João Wandeley Geraldi. Belo Horizonte: Autêntica, 2015.

MÈLICH, J-C. Ética de la compasión. Barcelona: Herder, 2010.

MÈLICH, J-C. Narración y hospitalidad. Anàlisi, n. 25, p. 129-142, 2000. Disponivel em: <http://
www.raco.cat/index.php/analisi/article/viewFile/15053/14894>. Acesso em: 30 jun. 2014.

MÈLICH, J-C. La sabiduría de lo incerto: sobre ética y educación desde un punto de vista literario. Revista Educar, n. 31, p. 33-45, 2003. Disponivel em: <http:// educar.uab.cat/article/view/303>. Acesso em: 01 out. 2015.

MÈLICH, J-C. La sabiduría del silencio: ensayo para una lectura pedagógica del Tractatus de Wittgenstein. ARS BREVIS, n. 13, p. 220-241, 2007. Disponível em: <http://www.raco.cat/index.php/ArsBrevis/issue/view/8516/showToc>. Acesso em: 08 mai. 2014.

MÈLICH, J-C. La Lección. 2008. Disponível em: <https://www.academia.edu/7862733/La lecci\%C3\%B3n>. Acesso em: 12 jan. 2015.

OSINSKI, D. R. B. A autobiografia como fonte de investigação histórica para a Educação. Olhar do Professor, n. 12, p. 33-55, 2009. Disponivel em: <http:// www.revistas2.uepg.br/index.php/olhardeprofessor/ article/viewArticle/1561>. Acesso em: 15 jun. 2013.

SILVA, M. A língua absolvida: uma especulação para a formação de professores. Nuances, v. 4, p. 48-56, set. 1998. Disponível em <http://revista.fct.unesp. br/index.php/Nuances/article/viewFile/72/77>. Acesso em: 5 dez. 2012.

SOUZA, E. C.; CORDEIRO, V. M. R. Ato de viver? Ato de contar: escritas de si, memórias e histórias de leitura nos rascunhos de mim. In: SOUZA, E. C. (Auto) biografias e documentação narrativa: redes de pesquisa e formação. Salvador: EDUFBA, 2015. p. 297-306

SOUZA, R. M. As primeiras memórias de um leitor: Elias Canetti em Ruschuk. In: VICENTINI, P. P.; SOUZA, E. C.; PASSEGGI, M. C. Pesquisa (auto)biográfica: questões de ensino e formação. Curitiba: CRV, 2013. p. 189-200.

SOUZA, R. M. Como um escritor é lido? Sobre a apropriação de Elias Canetti pelas universidades brasileiras: Revista Plumilla Educativa (Colombia), n. 14, p. 225-238, 2014. Disponível em: <http://revistasum. umanizales.edu.co/ojs/index.php/plumillaeducativa/issue/view/54/showToc>. Acesso em: 05 abr. 2015. 
SOUZA, R. M. Antes de Auschwitz: ensaio sobre autobiografia e formação em Elias Canetti. 2015. $209 \mathrm{f}$. Tese (Doutorado em Educação) - Programa de PósGraduação em Educação e Contemporaneidade PPGEduC, Universidade do Estado da Bahia - UNEB, Salvador, 2015.
WITTGENSTEIN, L. Tractatus logico-philosophicus. Tradução de Luiz Henrique Lopes dos Santos. São Paulo: EDUSP, 2001.

Recebido em: 10.05.2016

Aprovado em: 12.07 .2016

Rodrigo Matos de Souza é professor do Centro Universitário Jorge Amado (UJ). Doutor em Educação e Contemporaneidade pela Universidade do Estado da Bahia, com doutorado sanduíche pela Universidad de Sevilla (PDSE-BEX/CAPES) e pela Universidade de São Paulo (PROCAD/CAPES). Pesquisador do GRAFHO/UNEB. É editor-executivo da Revista Brasileira de Educação de Jovens e Adultos e editor-assistente da Revista Brasileira de Pesquisa (Auto)Biográfica. Já esteve como professor visitante na Universidad Católica de Pereira e professor visitante do Doutorado em Formación en Diversidad da Universidad de Manizales. E-mail: rodrigomatos28@hotmail.com

Centro Universitário Jorge Amado / Coordenação das Licenciaturas

Rua Miguel Calmon, 32, Edf. Bradesco, Comércio, Salvador-BA, Cep 40.015-010.

Elizeu Clementino de Souza é Pesquisador 1D CNPq. Professor Titular do Programa de Pós-Graduação em Educação e Contemporaneidade, da Universidade do Estado da Bahia (PPGEduC-UNEB). Coordenador do GRAFHO (Grupo de Pesquisa (Auto)biografia, Formação e História Oral). Pesquisador associado do Laboratorie EXPERICE (Université de Paris 13 - Paris 8). Tesoureiro da Associação Brasileira de Pesquisa (Auto)biográfica (BIOgraph). Membro do Conselho de Administração da Association Internationale des Histories de Vie en Formation et de la Recherche Biographique en Education (ASIHIVIF-RBE). E-mail: esclementino@uol.com.br

Universidade do Estado da Bahia

Programa de Pós-Graduação em Educação e Contemporaneidade

Rua Silveira Martins, 2555 - Cabula, Cep 41195001 